\title{
A campanha difamatória contra a exposição Queermuseu
}

\section{The defamatory campaign against Queermuseu exhibition}

\begin{abstract}
Dária Jaremtchuk
É professora Livre Docente pela Escola de Artes, Ciências e Humanidades (EACH/USP), onde atua nos cursos de graduação. Também é docente no Pós-graduação em Artes Visuais da ECA/USP e Estudos Culturais da EACH/USP.
\end{abstract}

\section{Jorge Luiz Miguel}

É artista e pesquisador. Atualmente mestrando do Programa de Pós-Graduação em Artes Visuais da ECA-USP, sob orientação da professora Dária Jaremtchuk, onde realiza pesquisa sobre exposições censuradas e as guerras culturais no Brasil.

\section{RESUMO}

Este artigo procura reconstituir a campanha difamatória contra a exposição Queermuseu cartografias da diferença na arte brasileira, que levou a seu fechamento antecipado em setembro de 2017. Analisando os acontecimentos, observa-se a propagação de pânico moral em relação ao conteúdo de algumas poucas obras expostas, que serviram como exemplos para difundir a crença de que artistas estariam ligados a uma agenda política de esquerda interessada em corromper moralmente o público, ameaçar crianças e ofender a fé cristã. Pelo poder de manipulação e de influência sobre setores da sociedade, esse caso de censura tornouse um capítulo significativo da história das chamadas "guerras culturais" no Brasil.

PALAVRAS-CHAVE: Queermuseu; Guerras culturais; Censura; Artes visuais.

\section{ABSTRACT}

This article seeks to reconstruct a defamatory campaign against the exhibition Queermuseu Cartographies of Difference in Brazilian Art, which led to its early closure in September 2017. Analyzing the events, we observe a propagation of moral panic in relation to the content of some of the works exhibited, which served as examples to spread the claim that artists are linked to a left-wing political agenda interested in morally corrupting the public, threatening children and offending the Christian faith. Due to the power of influence over part of society, this case of censorship became a significant chapter in the history of the so-called "cultural wars" in Brazil.

KEYWORDS: Queermuseu; Culture wars; Censorship; Visual Arts.

\section{RESUMEN}

Este artículo busca reconstruir la campaña difamatoria contra la exposición Queermuseu Cartografías de la diferencia en el arte brasileño, que provocó su cierre anticipado en septiembre de 2017. Al analizar los hechos, observamos la propagación del pánico moral en relación al contenido de algunas obras expuestas, que servirán de ejemplo para difundir la 
creencia de que los artistas están vinculados a una agenda política de izquierda interesada en corromper moralmente al público, amenazar a los niños y ofender la fe cristiana. Debido al poder de manipulación e influencia sobre sectores de la sociedad, este caso de censura se convirtió en un capítulo significativo en la historia de las llamadas "guerras culturales" en Brasil.

PALABRAS CLAVE: Queermuseu, guerras culturales, censura de las artes visuales

Submetido em 10 de Junho de 2021

Aceito em 24 de Setembro de 2021

\section{Introdução}

A história das chamadas "guerras culturais" tem no fechamento da exposição Queermuseu - cartografias da diferença na arte brasileira uma etapa recente e importante na escalada de manipulação ideológica e de autoritarismo no país. A repercussão das denúncias contra a mostra alertou grupos conservadores, que transformaram outros artistas e instituições culturais em alvo de uma perseguição moral de proporções inéditas, recolocando a censura como uma ameaça ao conjunto do cenário artístico.

No contexto de recomposição da direita brasileira no período recente, posições que eram marginais passaram a ocupar o centro do debate político. 0 combate à suposta "doutrinação política" nas escolas e universidades, a interdição do debate sobre igualdade de direitos entre homens e mulheres, entendido como expressão de uma perigosa "ideologia de gênero" a ser combatida, a ascensão do fundamentalismo religioso cristão e um ressurgimento da pregação anticomunista configuram um cenário ideológico conservador, no qual os ataques às artes se somaram à ofensiva contra os direitos das mulheres, indígenas, LGBTs, da população negra e dos trabalhadores em geral.

Em instrumento importante para o avanço da agenda conservadora tem sido a promoção de pânicos morais. Nesse processo, grupos sociais são retratados como uma ameaça a valores básicos da sociedade, mobilizando uma parcela da população contra esses “infratores” e justificando medidas drásticas contra eles. Desde 2017, muitos artistas sentiram na pele os efeitos do pânico moral, na medida em que uma campanha difamatória foi bemsucedida em colocar sob suspeita todo o campo das artes, difundindo a crença de que artistas e 
obras estariam ligados a uma agenda política de esquerda responsável por corromper moralmente o público, ameaçar crianças e ofender a fé cristã.

O propósito deste artigo é reconstituir a campanha difamatória contra a Queermuseu, das primeiras denúncias realizadas em texto e vídeo passando por sua difusão nas mídias até o fechamento da exposição, determinado pelo Grupo Santander, patrocinador do evento. Entende-se que essa recuperação factual permite perceber como o pânico moral se instalou, para depois expandir-se, atingindo alvos distantes da própria exposição.

\section{Primeiras denúncias}

A exposição Queermuseu - cartografias da diferença na arte brasileira, com curadoria de Gaudêncio Fidelis, foi inaugurada em 15 de agosto de 2017, no Santander Cultural, em Porto Alegre e durante as primeiras semanas teve ampla visitação, sem maiores ocorrências. Com 263 obras de 85 artistas brasileiros, o curador utilizou o termo queer em um sentido bastante amplo para envolver assuntos relativos às diferenças de gênero, sexualidade e mesmo raça ${ }^{1}$. Para a instituição patrocinadora, o Grupo Santander, Queermuseu era uma espécie de manifesto em defesa da diversidade ${ }^{2}$.

As repercussões negativas do evento iniciaram-se na manhã do dia 6 de setembro, quando foi publicada a matéria "Santander promove pedofilia, pornografia e arte profana em Porto Alegre" no Lócus Online, de Passo Fundo, portal de notícias com perfil conservador ${ }^{3}$. Cesar Augusto Cavazzola Junior, autor do texto, é advogado, professor de Direito e ex-aluno do curso online de filosofia do jornalista Olavo de Carvalho ${ }^{4}$. Segundo relatou à revista Época, ele

\footnotetext{
1 Segundo seu curador, Gaudêncio Fidelis, "o termo queer, tal como é introduzido nesta exposição, constitui uma porta de entrada para tratar de um conjunto de questões articuladas em torno da diferença, das expressões de gênero, da sexualidade e da diversidade (de gênero e formas por consequência)" (FIDELIS, 2017 p 12).

2 Nas palavras do presidente do Grupo Santander no Brasil, Sérgio Rial, ao apresentar o catálogo da exposição: "o que é diverso e tem multiplicidade, seja na área cultural ou étnica, na crença ou na linguística, ganha cada vez mais atenção por parte da nossa organização (...) trata-se de um valor para nossa empresa, pois acreditamos que a diversidade é a impulsora da criatividade e da eficiência" (FIDELIS, 2017, p 3).

3 Disponível em: <www.locusonline.com.br/2017/09/06/santander-cultural-promove-pedofilia-pornografia-earte-profana-em-porto-alegre/>. A matéria é ilustrada com 14 fotografias feitas pelo autor, onde aparecem 20 das 263 obras da exposição.

4 Olavo de Carvalho (1947 - ) é escritor e jornalista brasileiro. Começou sua carreira dando cursos e escrevendo sobre astrologia e, por um período, pertenceu a uma corrente esotérica do islamismo. Nos anos 1990, com a publicação de seu livro A nova era e a revolução cultural: Frijtof Capra e Antonio Gramsci, Carvalho passou a divulgar e adaptar ideias do neoconservadorismo norte-americano para o contexto brasileiro, escrevendo para a
} 
havia visitado a exposição pouco antes, o que lhe possibilitou produzir as imagens que ilustram a publicação (Tavares; Amorim, 2017).

Cavazzola tem por objetivo desmascarar a mostra que, segundo ele, atenderia a uma agenda oculta de esquerda. Em artigos anteriores para o Lócus Online, onde fazia uma defesa do projeto Escola Sem Partido, o advogado já tinha se posicionado contra o marxismo cultural. Essa tese, com origem em círculos conservadores norte-americanos, teve na figura de Olavo de Carvalho um dos seus primeiros divulgadores no Brasil ${ }^{5}$. Os opositores do chamado "marxismo cultural" acreditam que o movimento comunista internacional teria mudado de tática, passando a patrocinar a tomada das instituições culturais a fim de destruir a cultura ocidental, com base em ideias erroneamente atribuídas a Antonio Gramsci.

Imbuído dessas premissas, Cavazzola pretendeu expor os desígnios ocultos da Queermuseu. Qualificando o curador da exposição, Gaudêncio Fidelis, como um "especialista em confusão" e um "depravado", para quem "a tradição não tem qualquer papel numa sociedade a não ser oprimir desejos insaciáveis" (Cavazzola Junior, 2017, s/p), o autor do texto repudiava veementemente o discurso antinormativo da curadoria.

Segundo Cavazzola, a Queermuseu atendia a agenda de movimentos de minorias que "não querem igualdade coisíssima nenhuma, mas a criação de amplos poderes para formação de classes de intocáveis" (Cavazzola Junior, 2017, s/p). Nessa acusação é possível reconhecer os ataques de Olavo de Carvalho ao projeto de criminalização da homofobia, que replica também o lugar comum no discurso conservador para o qual seriam os próprios movimentos das mulheres, dos negros e de outros grupos sociais que gerariam as desigualdades por eles apontadas. Embora não seja tematizada, a orientação sexual do curador fundamenta as suspeitas expressas no texto, que inclui repetidas acusações de perversão. Cavazzola conclui o seu texto revelando que a própria civilização estava sendo ameaçada pela exposição. Diz ele:

Para os novos parâmetros da arte, a beleza pouco importa se o artista for capaz de causar espanto, de transgredir normas e inserir os seus trabalhos numa proposta de gênero. Poucos sabem que a arte é uma forma de transcender o barbarismo e as

grande imprensa brasileira, como 0 Globo, Folha de São Paulo e Zero Hora, entre outros. Desde 2005, vive nos Estados Unidos.

5 Sobre a origem "marxismo cultural", descrito como uma teoria da conspiração, ver o artigo de Jérôme Jamin, Cultural Marxism and the Radical Right, reunido no livro The Post-War Anglo-American Far Right: A Special Relationship of Hate. Londres: Palgrave Macmillan, 2014. 
limitações do imaginário humano, na busca incansável pelos altos picos de realização do homem: é um ato de defesa da civilização. (Cavazzola Junior, 2017, s/p).

Algumas das obras publicadas por Cavazzola acabaram por se tornar o centro da polêmica contra a exposição: a pintura Cruzando Jesus Cristo com Deusa Schiva, de Fernando Baril, em que um Cristo de vários braços está cercado de objetos contemporâneos; a obra Et Verbum, de Antonio Obá, uma caixa com réplicas de hóstias onde estão escritos nomes de partes do corpo, como ânus, vagina e língua; a pintura Cena de Interior II, de Adriana Varejão, inspirada no estilo da shunga, onde diversas práticas sexuais são retratadas; e duas pinturas de Bia Leite, Travesti da lambada e deusa das águas e Adriano bafônica e Luiz França She-há. Estas últimas foram posicionadas logo na abertura do artigo: para dar um efeito de destaque, um recorte da imagem foi reproduzido numa barra acima do título e a fotografia completa foi posicionada logo em seguida, enquadramento que serviu como um abre-alas da denúncia de "pedofilia, pornografia e arte profana em Porto Alegre" (cf. figura 1). Como as mesmas pinturas foram repetidas no meio do texto, pode-se inferir que elas adquiriram importância por talvez ilustrarem mais diretamente as teses do autor. Também é importante destacar que nenhuma das obras foi identificada e a exposição foi tratada no texto como um todo indistinto.

Figura 1: Abertura da matéria de Cavazzola na Lócus Online
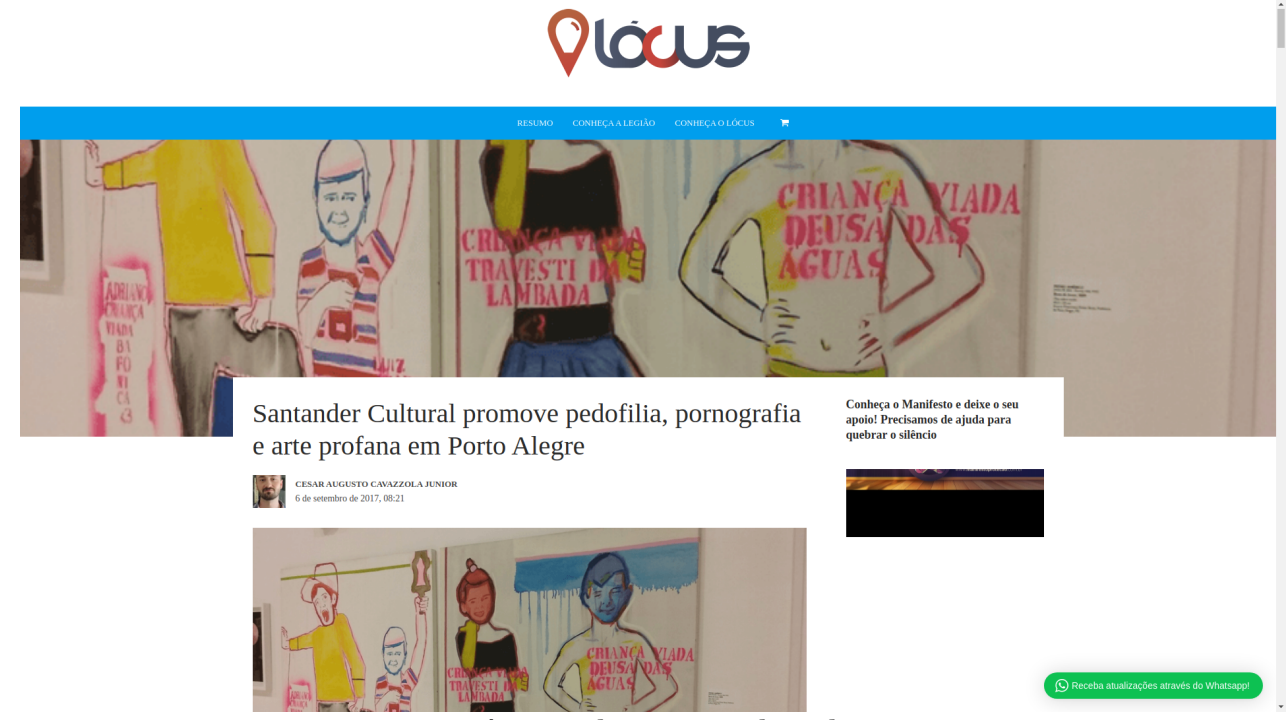

Fonte: Lócus Online. Setembro de 2017.

No mesmo dia da publicação do texto de Cavazzola Junior, o ativista Felipe Diehl gravou o vídeo "Pedofilia, zoofilia e hóstia de vagina", com 6 minutos de duração, que foi postado no 
Facebook e no Youtube no dia 8 de setembro. Diehl, que é segurança patrimonial e criador da página "Direita Gaúcha" no Facebook, já tinha lançado vídeos satirizando a esquerda, além de também ter organizado um "Rolezinho Reaça", encontro de jovens de direita na UFRGS, que desafiavam a suposta hegemonia de esquerda na instituição. Diehl, que era estudante naquela universidade, já havia sido acusado de ter ameaçado colegas durante uma ocupação, em 2016, e de andar armado no campus ${ }^{6}$.

O formato do vídeo de Diehl produzido no Santander Cultural estrutura-se como uma visita guiada à exposição, em que ele assume a função de mediador que, ao longo do percurso, apresenta as obras do Queermuseu para o público. Logo no início, ele refere-se às almofadas de tecido da obra FUCK, de Danilo Villa e, em seguida, volta a câmera para si mesmo e fala:

\begin{abstract}
[FUCK]
Esse é o recado que o Santander Cultural, esse é o recado que o Gaudêncio Fidelis tem pro povo gaúcho. Presta atenção: isso aqui eles chamam de arte. Eu vou mostrar agora, só putaria, só sacanagem, mas que aqui em Porto Alegre, no Santander Cultural, é reconhecido como arte. Preste atenção: há pouco, tinha crianças olhando essas artes aqui, pra começar: [mostra a pintura "Cruzando Jesus Cristo com Deusa Schiva", de Fernando Baril] escarnecendo a Cristo... presta atenção nas obras: é uma soma de putaria, sacanage, perversão, tudo incitando a pornografia, a pedofilia, e a putaria [se volta para as duas fotos "Sem Título" (2009), de Nino Cais]. Nesse vídeo vocês vão me ouvir falar várias vezes putaria, porque isso aqui é uma putaria, vejam só se isso aqui é arte [mostra a fotografia Fim de Jogo (série Camisa Brasileira) de Gilberto Perin, 2010]. Pegam fotos de homens nus... Vejam só se isso aqui é arte pessoal [Aponta para a fotografia "From Opus Three", de Alair Gomes]. Isso aqui é uma putaria. O curador dessa obra é o Gaudêncio Fidelis, esse cara devia tar preso. Isso aqui é uma perversão. Bom, é uma chinelage. Eu vou tentar mostrar, a obra é imensa, vou tentar mostrar, dar um pause aqui nesse [volta para a pintura de Fernando Baril] Na verdade não é uma obra, na verdade é uma... não tem nem nome, tchê. [para diante de Exu (Elegbará) (1980), de Nelson Faedrich] Ó o Satanás no meio hein. Desconstrução da sociedade e da civilização judaico-cristã. [close em duas colagens Sem título de Nino Cais (2016)] Quem pagou essa obra? [se aproxima das pinturas de Bia Leite] Vejam só: pura incitação à pedofilia, pura putaria, deixando os moleque virarem viado desde cedo (Diehl, 2017).
\end{abstract}

Na declaração surgem as preocupações do ativista com as pinturas de Bia Leite: estão "deixando os moleque virarem viado desde cedo". A desaprovação da homossexualidade aparece ao lado de uma preocupação com a preservação do corpo masculino. Com um pudor que chega a ser cômico Diehl denuncia que "pegam fotos de homens nus", diante da foto de

6 Cf. postagem da página no Facebook do movimento Afronte. Disponível em: < www.facebook.com/afrontenacional/videos/821148181358104 >. Acesso em: 2 abr. 2021.

Dossiê Guerras Culturais - https://revistaecopos.eco.ufrj.br/

ISSN 2175-8689-v. 23, n. 3, 2020

DOI: 10.29146/ecopos.v24i2.27709 
Gilberto Perin, onde um time de futebol troca de roupa no vestiário. Ao longo da filmagem, Diehl mostra-se escandalizado quando se depara com representações do corpo masculino nas obras.

Além das preocupações relativas à sexualidade e à masculinidade, as supostas ofensas ao cristianismo foram outro tema que motivou a indignação de Diehl, sobretudo quando se refere à pintura Cruzando Jesus Cristo com Deusa Schiva, de Fernando Baril, e à obra Et Verbum de Antônio Obá. Diehl as compreende como zombarias e piadas de mau gosto que evidenciam o desprezo por Cristo. Ao longo de sua narrativa, o "professor Olavo", Olavo de Carvalho, é trazido como referência 'teórica' para contribuir com as suas análises.

Figura 2: Felipe Diehl discursa para a câmera. À esquerda, fotografias da série Ecléticos, de Marcos Chaves.

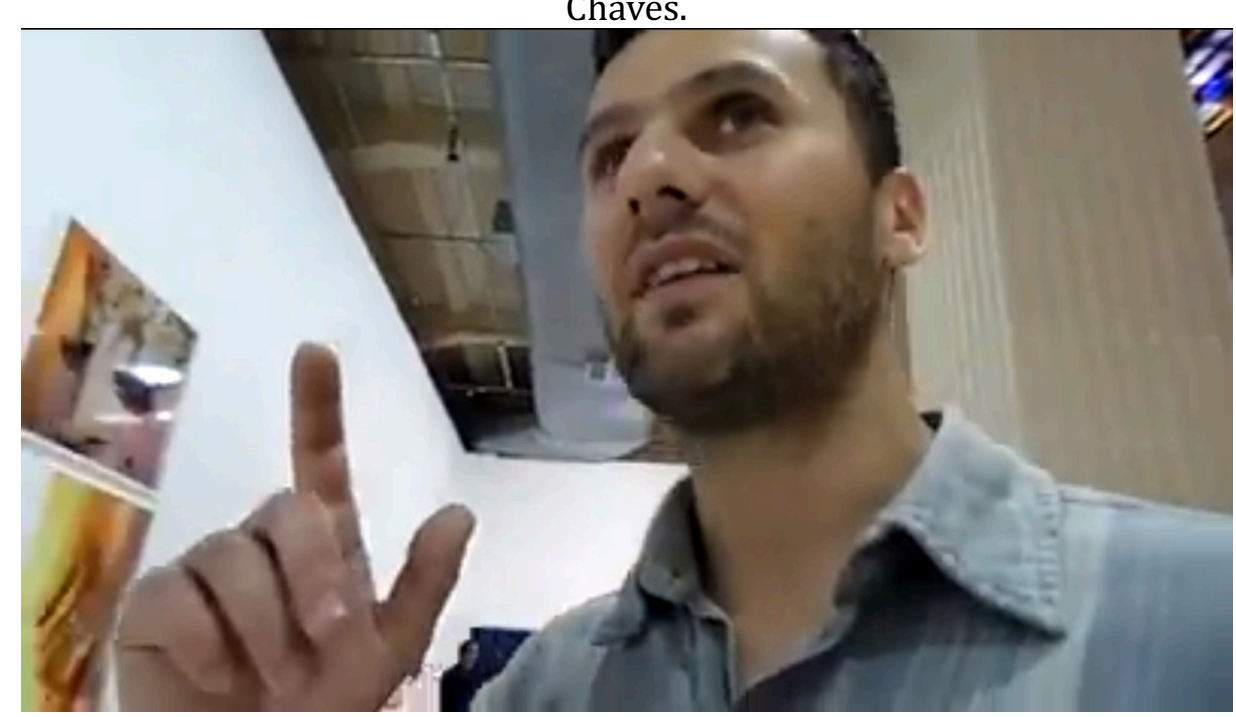

Fonte: vídeo de Diehl na página do Facebook de Magno Malta. Setembro de 2017.

Devido ao feriado de Independência do Brasil, no dia 7 de setembro, o Santander Cultural permaneceu fechado. Porém, no dia seguinte, Rafinha BK e Márcio Gonçalves Strzalkowski ${ }^{7}$ visitaram a exposição com a intenção de filmá-la. BK também trabalha como segurança patrimonial e, desde 2016, mantêm um canal no Youtube com conteúdos que criticam os movimentos sociais, as campanhas eleitorais de candidatos de esquerda e as ocupações estudantis. Utilizando-se do formato de entrevistas com os participantes desses movimentos, 7 Márcio Strzalkowski também é ativista conservador e youtuber, dono do canal "O Salsichão do Amor 2 - A
missão". 
Rafinha BK pretende demonstrar que seus interlocutores são desinformados, ou então, que não estão dispostos ao diálogo ${ }^{8}$.

No que se refere a mostra Queermuseu, BK produziu, com auxílio de Strzalkowski, “Denúncia: Santander Incentiva a Pedofilia!”, vídeo com 7 minutos de duração. Mais dinâmico que a produção de Diehl, nele BK, auxiliado por Strzalkowski, percorre a mostra com um papel dobrado na mão, um suposto roteiro para a filmagem, encontra rapidamente algumas obras (as pinturas de Baril, Varejão e Bia Leite e a obra de Obá recebem destaque) e, mais precisamente, diante das pinturas de Bia Leite, BK e Strzalkowski ambos conversam:

[Márcio] Por causa que justamente, criança viada, travesti da lambada [aparece no vídeo a legenda "CRIANÇA TRAVESTI", por sobre a imagem] da lombada - da lambada [BK] Cúmulo do absurdo!

[Márcio] Isso aqui é praticamente prostituição infantil. Nem mesmo um travesti vai concordar com essa imagem aqui. Nem mesmo um travesti vai pegar e vai dizer que ser travesti é uma coisa boa para uma criança.

[BK] Olha só pessoal, isso eles chamam de exposição no Santander Cultural (BK, 2017)

Em seguida, eles tentam filmar uma criança acompanhada de familiares que estava entre o público da mostra, mas BK é impedido e conduzido pelos seguranças para fora do prédio. Ainda com o roteiro nas mãos, com um largo sorriso no rosto, ele filma a própria expulsão, comentando: "olha só, os caras tão me tirando daqui a força, olha só o que eles tão fazendo, tem uma criança assistindo aquilo ali, ia filmar agora, os caras tão me tirando, olha isso, olha isso, pedofilia, pedofilia, exposição à pedofilia os caras tão fazendo" (cf. figura 3). Do lado de fora, BK ainda tenta convencer um segurança a dizer que a exposição é "pedofilia".

\footnotetext{
8 Felipe Diehl e Rafinha BK gravaram alguns vídeos juntos, como um vídeo em que eles discutem com participantes de uma ocupação estudantil numa universidade gaúcha, em 2017. Vídeo "Invadindo uma invasão Rafinha BK e Felipe Diehl invadindo a Unisinos", publicado em 14 de julho de 2017. Disponível em: < www.facebook.com/watch/?v=1419536234799925>Acesso em: 01 de março de 2021.
} 
Figura 3: Rafinha BK é expulso do Santander Cultural.

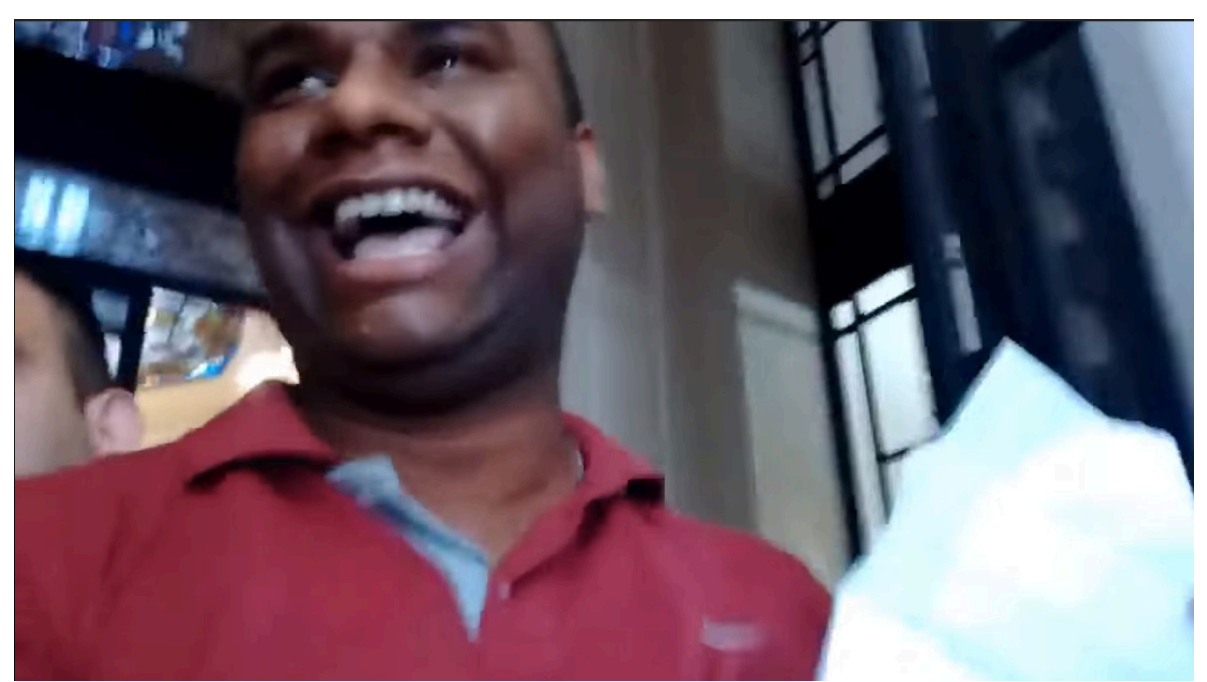

Fonte: canal de Rafinha BK no Youtube. Setembro de 2017.

\section{A difusão das denúncias}

O texto e as imagens publicadas por Cavazzola Junior, assim como os vídeos publicados por Diehl e BK, tornaram-se a base para as denúncias contra Queermuseu e, pode-se dizer, causaram o seu fechamento. A circulação desse material pelas redes propiciou que as imagens fossem reeditadas, as filmagens recombinadas e todo esse conteúdo transformado em um certo tipo de "prova" para as denúncias que se avolumaram. Assim sendo, as críticas à mostra e às obras expostas foram realizadas, em sua grande maioria, a partir desse material selecionado e editado e não com a aproximação direta entre o grande público e a produção dos artistas.

A campanha contra a Queermuseu difundiu-se, prioritariamente, pelo Facebook e pelo Whatsapp. Tendo como fonte o "Monitor do debate político no meio digital", projeto de pesquisa realizado pelo Grupo de Políticas Públicas para o Acesso à Informação (Geppis) da USP, foi possível retraçar a rede de envolvidos na difusão das denúncias, assim como resgatar algumas ações que foram feitas dentro e fora das redes ${ }^{9}$. Graças a essa pesquisa, pode-se conhecer quais foram os vídeos mais assistidos sobre a Queermuseu, as matérias e as postagens mais compartilhadas no Facebook até o dia seguinte ao fechamento da exposição.

${ }^{9}$ Coordenado pelo professor Pablo Ortellado, o projeto monitora conteúdo político de abrangência nacional que circula nas quatro maiores plataformas de redes sociais: Instagram, Twitter, YouTube e Facebook. Cf. MONITOR DO DEBATE POLÍTICO NO MEIO DIGITAL, Quem somos. Disponível em: <www.monitordigital.org/quem-somos>.

Dossiê Guerras Culturais - https://revistaecopos.eco.ufrj.br/

ISSN 2175-8689-v. 23, n. 3, 2020

DOI: 10.29146/ecopos.v24i2.27709 
Essas informações possibilitaram reconhecer o envolvimento de outros perfis e de diferentes postagens no Facebook. Na noite de 8 de setembro, por exemplo, a página "Resistência Conservadora" anunciava o evento "Terço em reparação dos sacrilégios no Santander Cultural", logo para o dia seguinte. Utilizando imagens feitas por Cavazzola Junior e o citando como fonte, a Queermuseu é assim resumida na convocação:

A exposição do Santander Cultural contém profanações, apologia à pedofilia, zoofilia, pornografia e homossexualismo. Escolas estão levando alunos para ver a exposição. Nossa Senhora insistiu nas aparições de Fátima que façamos atos de reparação pelos pecados com que Deus é ofendido. Por isso, sábado, às $18 \mathrm{~h}$, rezaremos um terço na frente do Santander, na Praça da Alfândega ${ }^{10}$.

Sobre esse evento, que ocorreu na praça da Alfândega, em frente ao espaço cultural, há um pequeno registro em vídeo com 10 pessoas em fileira ( 9 homens e 1 mulher), em que um dos participantes segura uma bíblia e se encarrega de puxar a oração "Ave Maria”. Cabe ressaltar que, além do pequeno grupo reunido, está Strzalkowski que realizou a filmagem ${ }^{11}$.

Figura 4: Terço em reparação dos sacrilégios no Santander Cultural

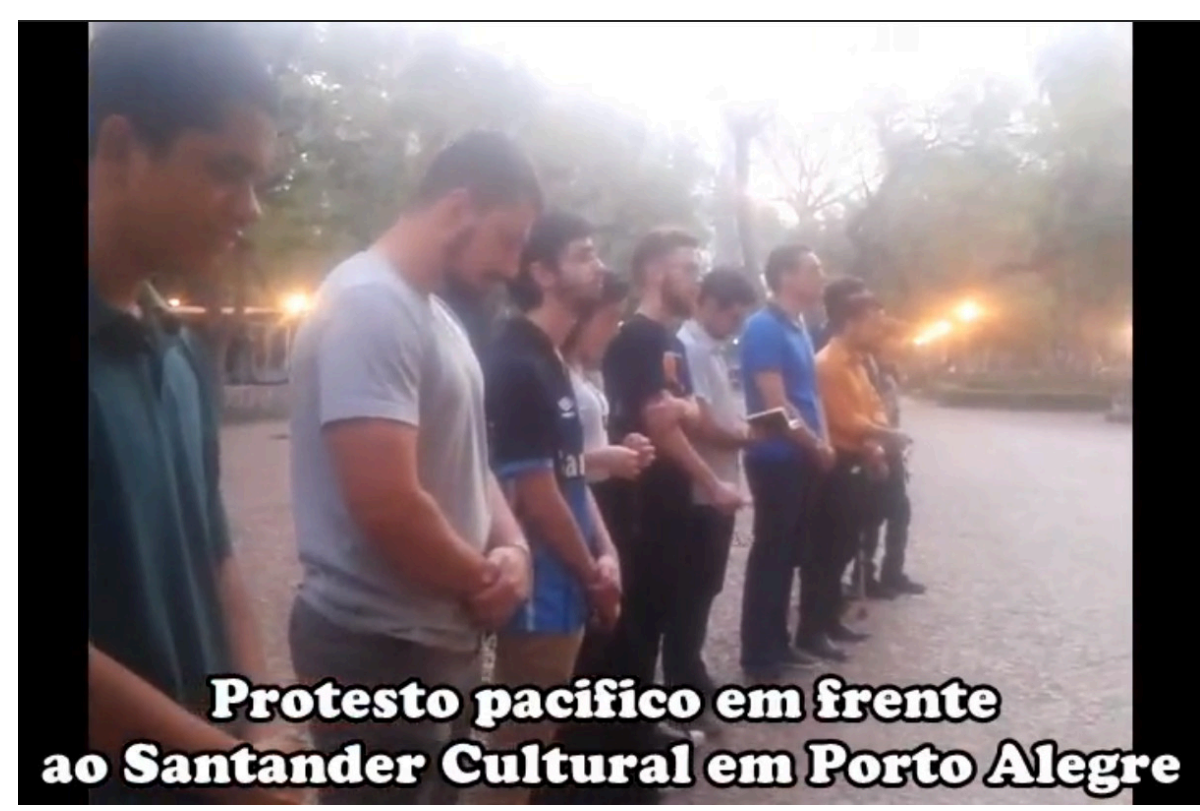

Fonte: canal de Márcio Strzalkowski no Youtube. Setembro de 2017

10 Descrição do evento "Terço em reparação dos sacrilégios no Santander Cultural", criado pela página "Resistência Conservadora". Disponível em: <www.facebook.com/events/140210453251619/>.

11 Vídeo "Queermuseu Porto Alegre - Protestos, Denúncias e Cancelamento" do canal de Strzalkowski. Disponivel em:<www.youtube.com/watch?v=oEyk4-rXxxI $>$. 


\section{DOSSIE}

Acompanhando os fatos de modo cronológico, na madrugada do dia 9 de setembro, o Centro Dom Bosco, organização de leigos católicos, compartilhou fotografias de obras da exposição produzidas por Cavazzola, com uma breve descrição dos fatos: "Ataques como esses às famílias e à fé estão cada vez mais comuns e isto precisa parar já!”. Essa postagem recebeu mais de seiscentos compartilhamentos.

Fundado em 2016, com sede no Rio de Janeiro, o Centro Dom Bosco se define como "uma família que reza, estuda e defende a fé"12 e tem por objetivo resgatar o catolicismo de antigamente. Segundo o professor Carlos Nougué, o nome faz referência ao sonho profético de Dom Bosco, em que o Brasil seria o último bastião da fé em tempos apocalípticos ${ }^{13}$.

Ainda no mesmo dia, 9 de setembro, foi criada no site da CitizenGO um abaixo-assinado contra a exposição. Com sede em Madri e ramificações em diversos países, a organização realiza petições em defesa de alguns valores: o direito à vida "desde a concepção até a morte natural", o direito a "honrar a Deus no âmbito privado e público" e o direito à propriedade privada, entre outros ${ }^{14}$. A CitizenGO foi trazida para o Brasil por Guilherme Ferreira, proprietário da editora Cristo Rei e próximo ao Centro Dom Bosco.

A petição da CitizenGO recebeu o título "Repúdio à exposição blasfema do Santander Cultural"15. Para ilustrar a subscrição, foram escolhidas três imagens: um detalhe da obra Et Verbum de Obá, onde se pode ler nas hóstias as palavras "vagina" e "língua", e as outras duas que se referem às pinturas de Fernando Baril e Bia Leite. Essa diminuta seleção de trabalhos expostos na Queermuseu tinha, muito provavelmente, o propósito de enfatizar as supostas ofensas à fé cristã, sem deixar de mostrar, por meio da obra que retrata crianças, a alegada "pedofilia". A adesão à petição autorizava o envio de um e-mail ao Santander, que revelava o nome do assinante junto à mensagem padrão. Até os dias de hoje, é possível contabilizar mais de cem mil assinaturas sem, contudo, ser possível identificar quantas o fizeram antes do fechamento da exposição. No texto enviado ao Santander podia-se ler:

12 Cf. CENTRO DOM BOSCO, Quem Somos. Disponível em:<centrodombosco.org/>.

13 Cf. postagem no Facebook de Carlos Nougué. Disponível em: <www.facebook.com/carlos.nougue.1/posts/131101600851068>.

14 Cf. CITIZENGO, Princípios (ethos) da Fundação CitizenGO. Disponível em: < $\underline{\text { https://www.citizengo.org/pt- }}$ br/principios-da-fundacao-citizengo $>$.

15 Disponível em: <www.citizengo.org/pt-pt/sc/88583-repudio-exposicao-blasfema-do-santander-cultural>. 
Escrevo para manifestar meu completo repúdio à exposição Queermuseu, que, sob a justificativa de divulgar "arte" (sim, entre aspas porque aquelas peças podem ser qualquer coisa, mas não arte), promove o escárnio ao cristianismo, a pornografia e até mesmo a pedofilia!

É uma vergonha uma empresa do porte do Santander apoiar uma iniciativa tão grotesca. Aprendam uma lição básica: o movimento LGBT usa a bandeira da tolerância para escarnecer, atacar e vilipendiar aquilo que outros consideram sagrado e ao mesmo tempo não toleram nenhum tipo de crítica! [grifos no original] (Citizengo, 2017)

Além dessa movimentação, no mesmo dia 9 de setembro, o portal de notícias Terça Livre e o Movimento Brasil Livre (MBL) publicaram textos e vídeos condenando a exposição, o que resultou em grande impulso à campanha difamatória. Na manhã desse dia, o MBL publicou no site Jornal Livre "Santander Cultural promove pornografia e até pedofilia com base na Lei de Incentivo à Cultura"16, utilizando as fotografias de Cesar Cavazzola e citando-o como fonte. Contudo, o texto enfatiza a informação de que a exposição foi financiada pela Lei de Incentivo a Cultura, isto é, com "dinheiro tirado dos pagadores de impostos", nas palavras dos autores ${ }^{17}$. Segundo o "Monitor do debate político no meio digital", este foi o segundo texto mais compartilhado sobre a Queermuseu, ultrapassado apenas pela matéria original de Cavazzola Junior (Monitor, 2017) ${ }^{18}$. Cabe aqui lembrar que o MBL, que surgiu no país após a reeleição da presidente Dilma Rousseff, conseguiu vasta capilaridade nacional pela forte campanha a favor do impeachment da presidente. Segundo seu coordenador nacional, Renan Santos, antes mesmo da divulgação do texto na internet, "células do movimento em todo o país receberam avisos sobre a exposição e um foi repassando para o outro" pelo WhatsApp, movimentação que explica em parte as proporções do alcance da campanha (Tavares; Amorim, 2017).

No final da tarde do dia 9 de setembro o portal de notícias Terça Livre publicou no Facebook um vídeo intitulado "Exposição Criminosa no Santander Cultural”, com 4 minutos de duração19. Segundo o "Monitor do debate político na internet", este foi o segundo vídeo mais visto até a manhã do dia 11 de setembro, com 673 mil acessos ${ }^{20}$. No formato de resumo dinâmico, o vídeo intercala cenas dos vídeos de Diehl e BK. Ao contrário dos materiais que

\footnotetext{
16 O site do Jornal Livre foi retirado da internet. Mas, por meio de reproduções da matéria em outros sites, tivemos acesso a seu conteúdo.

17 A questão do financiamento era mencionada no texto original, mas não enfatizada. Texto reproduzido em: <www.sramos.net/2017/09/absurdo-santander-cultural-promove.html>.

18 Disponível em: <www.facebook.com/monitordodebatepolitico/posts/1535646699830121>.

19 Disponível em: <www.facebook.com/1499604770306657/videos/1906769406256856>.

200 vídeo mais visto, da página "Fora Foro de São Paulo", não está mais disponível.
} 


\section{DOSSIÊ}

originaram a campanha, as imagens sexualmente explícitas foram censuradas: algumas foram desfocadas e outras cobertas com tarjas pretas onde se lê "censurado" (cf. figuras 5 e 6). Mesmo privado do conteúdo das imagens, o espectador ouve o julgamento proferido pelos autores dos vídeos. Dessa forma, enquanto algumas colagens e fotografias homoeróticas foram ocultas, as obras de Fernando Baril, Bia Leite e Antonio Obá são expostas integralmente. No caso da pintura de Adriana Varejão, as tarjas são pequenas, para que a zoofilia, alvo de denúncia, fique em evidência (cf. figura 6).

À medida que essas denúncias ganhavam maiores proporções, surgiam propostas de ações virtuais coordenadas para manifestar o repúdio a exposição. Entre elas, destaca-se o rebaixamento da nota da página do Santander Cultural no Facebook. Como o site permite avaliar as suas páginas numa escala que vai de 1 a 5, até segunda-feira, dia 11 de setembro, mais de vinte mil pessoas tinham concedido ao Centro Cultural a nota de menor valor, o que resultou na pontuação com o score final de $1,4^{21}$.

Figura 5: Vídeo do Terça Livre.

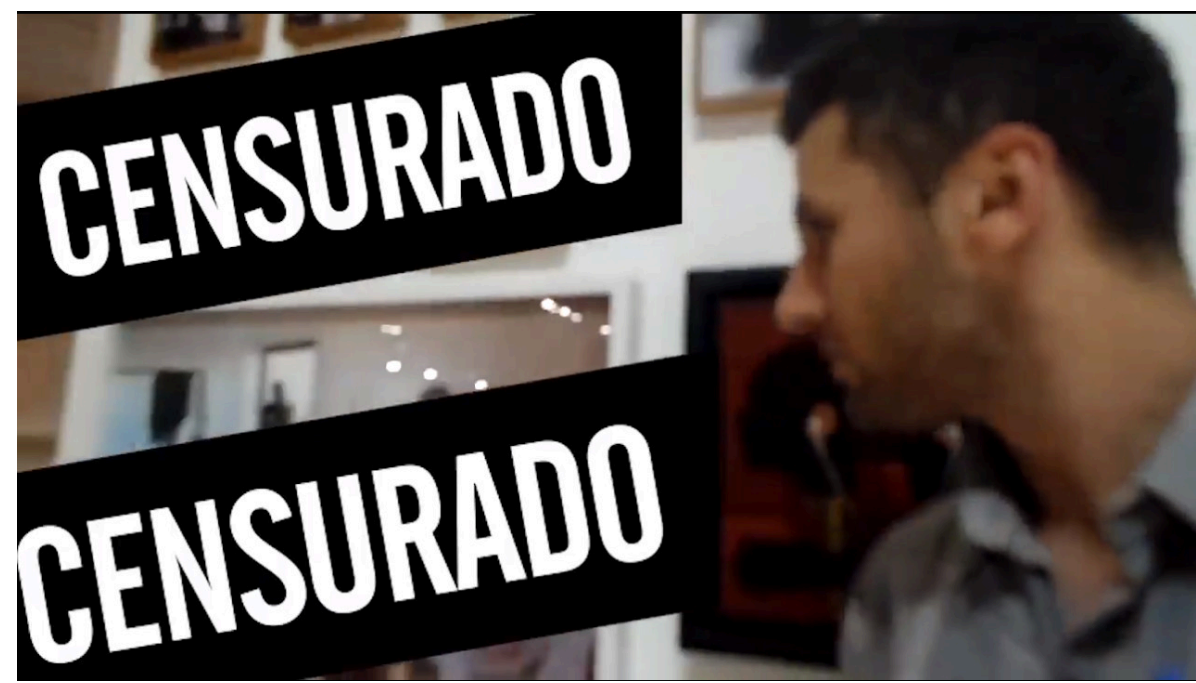

Fonte: página do Facebook do Terça Livre. Setembro de 2017.

Figura 6: Vídeo do Terça Livre.

21 Conforme informações da Agência Lupa, de checagens de fatos, na matéria "O Santander perdeu mesmo mais de 20 mil clientes em apenas dois dias?", autoria de Leandro Resende, publicada em 16 de setembro de 2017. Disponível em: <piaui.folha.uol.com.br/lupa/2017/09/16/santander-correntistas-queermuseum/>.

\section{Dossiê Guerras Culturais - https://revistaecopos.eco.ufrj.br/}




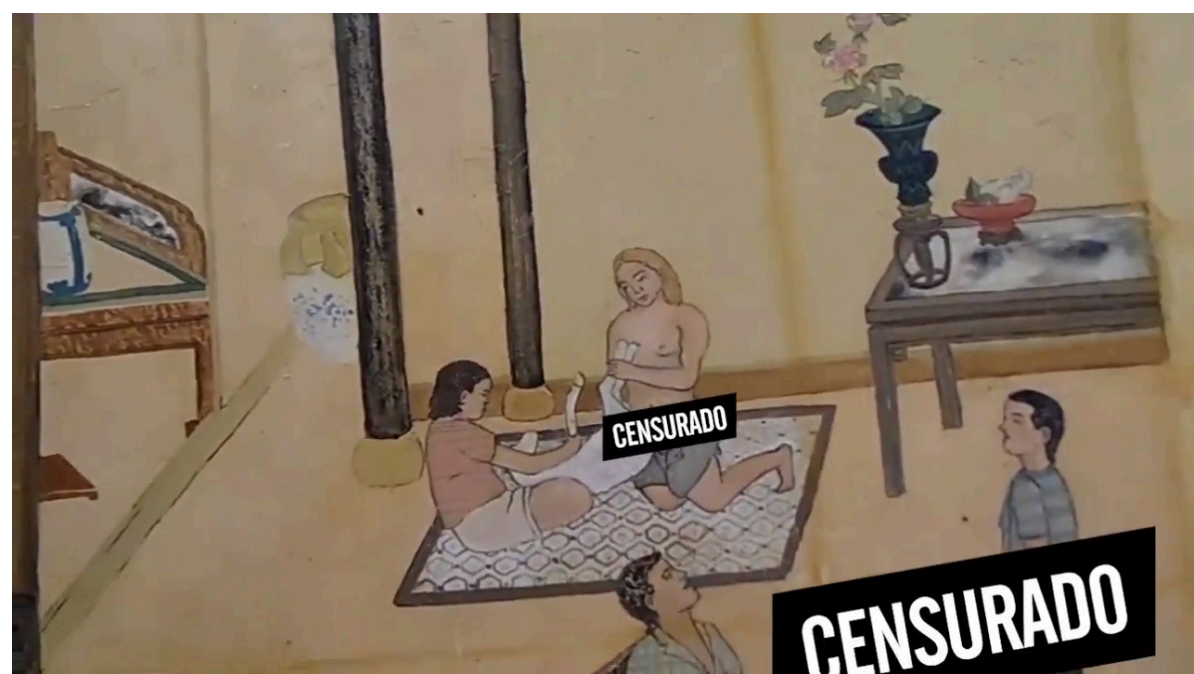

Fonte: página do Facebook do Terça Livre. Setembro de 2017.

Nesse processo, diversas pessoas declararam a intenção de encerrar a conta no Santander e algumas circularam imagens com cartões do banco quebrados (cf. figura 7). Um evento criado no Facebook pedindo o encerramento de contas no Santander teve mil participantes confirmados 22 . No entanto, pela falta de dados, não é possível precisar a quantia exata desses encerramentos. Após o fechamento da exposição, circulou nas redes sociais a informação de que 20 mil contas haviam sido fechadas, mas essa quantia foi desmentida pelo próprio Santander, consultado por uma agência de checagem (Resende, 2017).

Figura 7: Cartões do Santander quebrados.

22 Cf. Evento "Encerrar minha conta no Santander". Disponível em: <www.facebook.com/events/737660083109222/>. Acesso em 17 mar. 2021. 


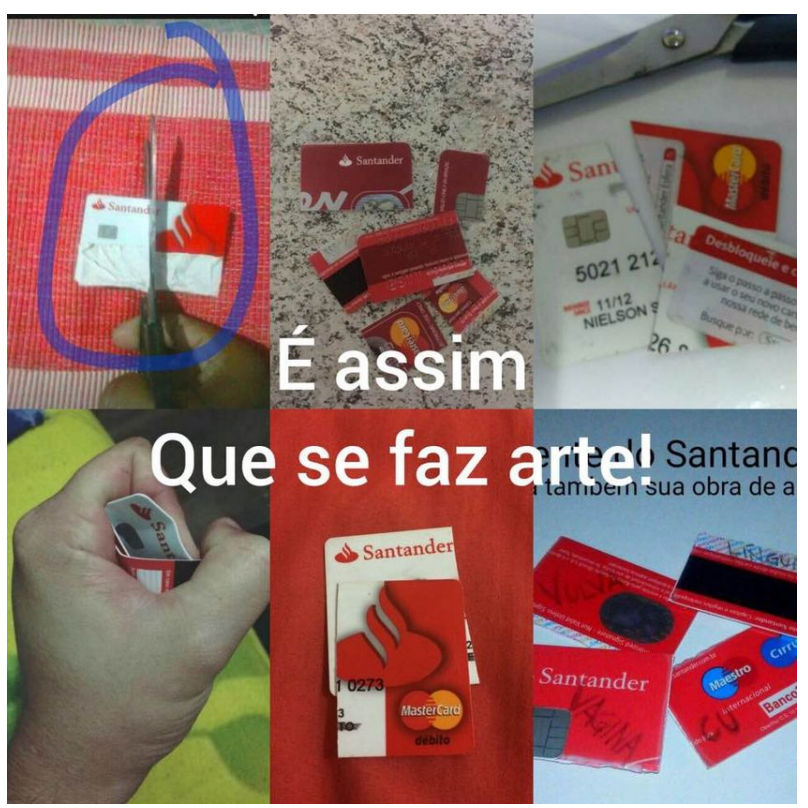

Fonte: Facebook. Setembro de 2017.

Para além das movimentações ocorridas na Internet, as ações contrárias à exposição não se limitaram à gravação dos vídeos e ao ato religioso presencial. Há relatos de violência, com agressões verbais e intimidação do público e dos artistas, ameaças ao curador e aos funcionários do próprio banco, e também pichação de agências bancárias. 0 jornal Zero Hora, por exemplo, noticiou:

Frequentadores do espaço relataram nas redes sociais que, no sábado [9 de setembro], foram alvo de agressões verbais dirigidas por pessoas que faziam registros em vídeo da exposição criticando o seu conteúdo. Pelo menos uma agência do Santander nas imediações do prédio da Praça da Alfândega foi pichada com frases como "Banco Santander apoia pedofilia" e "são anticristãos (sic)" (Zero Hora, 2017).

A revista Época, a partir de fontes ligadas ao banco Santander, revelou que pelo menos três diretores sofreram ameaças de morte por telefone e ao menos um funcionário foi agredido fisicamente. Nessa perspectiva, teriam sido esses eventos que levaram ao fechamento da exposição. Entretanto, Gaudêncio Fidelis, o curador da mostra, contesta essa versão ao dizer que ele passou a ser ameaçado depois de encerramento da Queermuseu (Tavares; Amorim, 2017). Assim sendo, é difícil precisar os fatos, haja vista que nem o Santander, os seus funcionários ou o curador abriram boletim de ocorrência sobre as violências sofridas ou fizeram algum tipo de notificação oficial e pública. 
Ainda sobre as acusações de agressões, Felipe Diehl negou que as tenha praticado. Em suas palavras: "Nós ganhamos o Santander em rezas de terços e orações. Aí é que se concentra a luta" (Tavares; Amorim, 2017).

\section{0 fechamento da exposição}

No dia 10 de setembro, um domingo, a exposição não abriu ao público ${ }^{23}$. A decisão surpreendeu também o curador, que revelou à imprensa ter sido avisado por amigos por meio do WhatsApp ${ }^{24}$. No início da tarde, o banco publicou na página do Santander Cultural Facebook a "Nota sobre a exposição Queermuseu"25. Pouco antes, a instituição havia retirado, desse mesmo endereço, todo o conteúdo referente à mostra, como fotografias e postagens.

A direção do banco Santander, ao decidir cancelar a exposição de forma unilateral, sem dar qualquer tipo de resposta à campanha difamatória, terminou por ratificar as posições dos grupos conservadores. A rapidez com que o patrocinador cedeu às pressões revelou 0 descompromisso da instituição com agentes do meio das artes envolvidos no processo e com qualquer debate a respeito do conteúdo artístico da mostra. Com uma nota explicativa, pedindo "sinceras desculpas a todos os que se sentiram ofendidos por alguma obra que fazia parte da mostra" (Santander Brasil, 2017), o banco não defendeu a proposta ou rebateu as versões parciais e preconceituosas que repercutiram nas mídias sociais.

O Santander transferiu o ônus para o curador da exposição, se eximindo de qualquer responsabilidade. Na nota, o banco define os objetivos de seu centro cultural nos seguintes termos: "incentivar as artes e promover o debate sobre as grandes questões do mundo contemporâneo (...) dar luz ao trabalho de curadores e artistas brasileiros para gerar reflexão". Afirma que tudo isso é feito "sem interferir no conteúdo para preservar a independência dos autores, e essa tem sido a maneira mais eficaz de levar ao público um trabalho inovador e de qualidade" (Santander Brasil, 2017). Contudo, no caso da mostra Queermuseu essas premissas não se efetivaram porque a instituição não dialogou ou criou oportunidade para que o curador

\footnotetext{
23 Segundo noticiou o site G1, apenas a exposição ficou fechada, sendo que o café, o cinema e a loja no interior do Santander Cultural receberam o público normalmente. Disponível em: <g1.globo.com/rs/rio-grande-dosul/noticia/museu-de-porto-alegre-encerra-exposicao-sobre-diversidade-apos-ataques-em-redes-socias.ghtml>.

${ }^{24} \mathrm{Cf}$. declarou a diversos jornais, tal como o Zero Hora na matéria acima citada.

25 Disponível em: <www.facebook.com/santanderbrasil/posts/10154720373470588/>.
} 


\section{DOSSIÊ}

se posicionasse ou os artistas se manifestassem sobre os seus próprios trabalhos. Prevaleceu a arbitrariedade e a censura provocadas por ações de setores exógenos às artes que colocaram em cena questões de decoro moral.

Ao falar em qualidade, o banco entende que a justificativa para cassar essa suposta independência está na desqualificação da mostra, à qual adere. Usando uma linguagem polida para revestir uma afirmação brutal, a nota diz:

Desta vez, no entanto, ouvimos as manifestações e entendemos que algumas das obras da exposição Queermuseu desrespeitavam símbolos, crenças e pessoas, o que não está em linha com a nossa visão de mundo. Quando a arte não é capaz de gerar inclusão e reflexão positiva, perde seu propósito maior, que é elevar a condição humana. (Santander Brasil, 2017)

A instituição acabou por subscrever, sob o título geral de "desrespeito", as acusações à exposição. Ao falar no "propósito maior" da arte, o banco demonstra uma convergência com concepções artísticas antiquadas e moralistas contrárias à mostra - basta recordar a definição de Cavazzola, segundo a qual "a arte é uma forma de transcender o barbarismo e as limitações do imaginário humano".

A capitulação expressa na nota e no fechamento da exposição não foram suficientes para que a imagem do Santander ficasse ilesa. Nos comentários à postagem do banco, que totalizaram mais de 28 mil, há muitas manifestações que consideravam a explicação dada insuficiente e pediam punição aos responsáveis pela exposição. Opositores à Queermuseu passariam a chamar o Santander de "Satander", "Satãder" ou "Satãnder", isto é, o banco de Satã. Esse trocadilho daria margem a diversas imagens de protesto (cf. figura 8). 
Figura 8: Protesto contra o Santander.

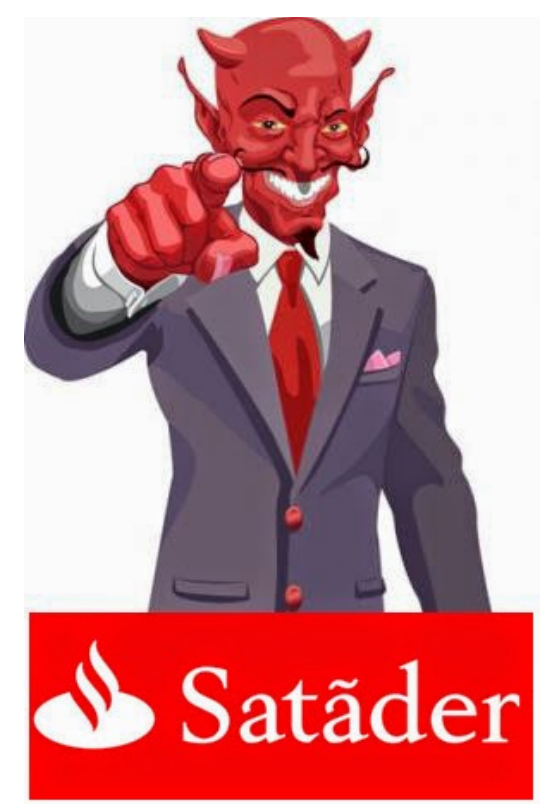

Fonte: Facebook. Setembro de 2017

Para os defensores da exposição, seu fechamento trouxe um dilema. Como rememorou seu curador, Gaudêncio Fidelis, num bom resumo da questão:

Como é que nós lidamos com uma exposição que está sendo atacada sistematicamente, em que há uma narrativa difamatória que só cresce, e não temos mais a exposição aberta para constatar se o que está sendo dito é verdade ou não? (FIDELIS, 2018) ${ }^{26}$

Ao impedir o acesso do público à mostra, a instituição tornou instantaneamente o portentoso prédio do seu espaço cultural um monumento à vitória moral dos perseguidores de da Queermuseu. Ao longo do domingo, dia do fechamento da mostra, diversos políticos e ativistas conservadores gravariam vídeos em frente ao Santander Cultural, comemorando a vitória. O fechamento da exposição foi noticiado pelos principais veículos de imprensa, tornando a Queermuseu um assunto de grande repercussão. No debate público que se seguiu, novos argumentos seriam brandidos e novas denúncias feitas.

${ }^{26}$ Disponível em: <apublica.org/2018/08/eu-recebi-mais-de-cem-ameacas-de-morte-diz-curador-da-exposicaoqueermuseu/>. 


\section{Desdobramentos}

Imediatamente após o fechamento da exposição, ocorreram tentativas de censura e intimidação a outras manifestações artísticas. Destacamos, entre outros incidentes, a apreensão pela polícia do quadro "Pedofilia" da artista Alessandra Cunha, retirado do Museu de Arte Contemporânea de Campo Grande e a proibição judicial da apresentação da peça “0 evangelho segundo Jesus - Rainha do céu", protagonizada pela atriz trans Renata Carvalho, em Jundiaí, em 15 de setembro de 2017. Houve ainda a ofensiva contra a performance La Bête, de Wagner Schwarz, realizada no âmbito da abertura do $35^{\circ}$ Panorama da Arte Brasileira do Museu de Arte Moderna de São Paulo, no final de setembro. Neste episódio, um vídeo descontextualizado de uma criança interagindo com o artista circulou como falsa evidência de uma suposta "erotização infantil", causando comoção nas redes sociais, perseguição ao artista e à mãe da criança, além de manifestações contrárias ao MAM SP e agressão física a funcionários do museu. 0 prefeito de São Paulo à época, João Dória, revelou a sua concordância com os manifestantes contrários à obra, declarando que "tudo tem limite".

Já no começo de outubro de 2017, o então prefeito do Rio de Janeiro, Marcelo Crivella, proibiria a realização da Queermuseu no Museu de Arte do Rio, que estava em negociação com a instituição carioca. Crivella gravou um vídeo afirmando que a exposição deveria ir "para o fundo do mar". Estes e outros casos abriram precedentes para o cerceamento à liberdade de expressão artística, processo este que permanece em curso na sociedade brasileira.

A campanha contra a Queermuseu e seus desdobramentos são mais bem compreendidos quando se observa o surgimento e a organização de grupos conservadores no Brasil, fenômeno que se acentuou após o golpe contra a presidente Dilma Rousseff, em 2016. Em determinado momento, setores críticos aos governos do Partido dos Trabalhadores, como os organizados sob o Movimento Brasil Livre, viram-se sem pauta para mobilizar a indignação de seus seguidores e transformaram as artes em alvo de seus ataques. Este processo tem ligação com ofensivas conservadoras no campo da educação, como as capitaneadas pelo movimento Escola Sem Partido (ao qual o MBL se associou no período), além do combate à "ideologia de gênero" feito por setores católicos e evangélicos (Miguel, 2016). Nesse processo, é importante lembrar que o conservadorismo se tornou um fenômeno global, que se espraia em diversos 


\section{DOSSIE}

movimentos contrários à igualdade de gênero e outras pautas consideradas de esquerda (Padro; Corrêa, 2018).

Como lembra Luísa Duarte, na apresentação do livro "Arte, censura, liberdade - reflexões à luz do presente", coletânea de artigos escritos no calor dos acontecimentos, a "censura era, no âmbito nacional, um substantivo feminino destinado aos livros de história quando se referiam à ditadura militar" até que, em 2017, uma série de episódios recolocou o problema no meio artístico com proporções surpreendentes. Embora campanhas de cunho moral não sejam inéditas no Brasil no campo das artes, a fúria e a proporção dos ataques realizados no período aqui discutidos colocaram o caso Queermuseu como inaugurando um novo patamar da questão no campo das artes.

Pode-se dizer que este episódio apontou para a fragilidade das instituições no país que abrigam exposições de artes visuais. Dependentes do modelo de produção e circulação viabilizado pelo dinheiro público de renúncia fiscal, esse mecanismo não está submetido a um efetivo controle democrático. Como aqui se discutiu, o Santander Cultural, assim como outros espaços culturais associados aos bancos e às corporações, utiliza-se desse dispositivo fiscal para promover as artes como uma forma de marketing institucional. Falta um efetivo compromisso desses espaços privados com o ambiente democrático ou com o fortalecimento das artes porque suas condutas se pautam em diretrizes mercantis e promoção da autoimagem corporativa.

Observa-se que, após a onda de ataques aqui apresentada, inúmeras instituições culturais e espaços museológicos públicos e privados no país tomaram atitudes cautelosas e se calçaram com instrumentos legais para abrigarem exposições com possível teor sexual ou moral. Cabe aqui como exemplo a decisão do Museu de Arte de São Paulo que abriu em outubro de 2017 a mostra "Histórias da Sexualidade" com restrição de entrada a menores de 18 anos, mesmo acompanhados dos responsáveis. Após manifestação do Ministério Público, o museu retirou essa determinação, excessiva mesmo diante da cautela necessária naquele momento ${ }^{27}$.

Seguramente, esse ambiente de permanente vigilância e censura produz inquietudes e cautela, o que leva ao acionamento da autocensura frente a casos que oferecem riscos. É possível se perguntar quantas exposições e ações culturais ligadas a temas candentes, como

${ }^{27}$ Disponível em: <revistacult.uol.com.br/home/historia-sexualidade-classificacao-indicativa-censura/> . 


\section{DOSSIÊ}

religião e sexualidade, não deixaram de ser realizadas em virtude da mudança no clima social e político do país. Ainda que as instituições se amparem na legalidade para não precisarem fechar eventos, a autocensura, nem sempre empregado de modo consciente, é um mecanismo cruel de preservação. Em muitos casos, evitar na organização de uma exposição certos temas, obras e artistas representa o triunfo do controle pelo medo e a capitulação a um meio cultural reacionário.

A indignação suscitada pela campanha difamatória na Queermuseu também revela a distância entre grande parte da população brasileira e o acesso às artes, haja vista que toda a indignação suscitada pelo caso se sustentou no discurso moral explorado pelos grupos conservadores sem que houvesse contato do público com as obras ou mesmo envolvimento com as prerrogativas da curadoria. Enfrentar essas questões estruturais se torna relevante para defender a liberdade de expressão no país.

Figura 9: Protesto contra a censura à Queermuseu.

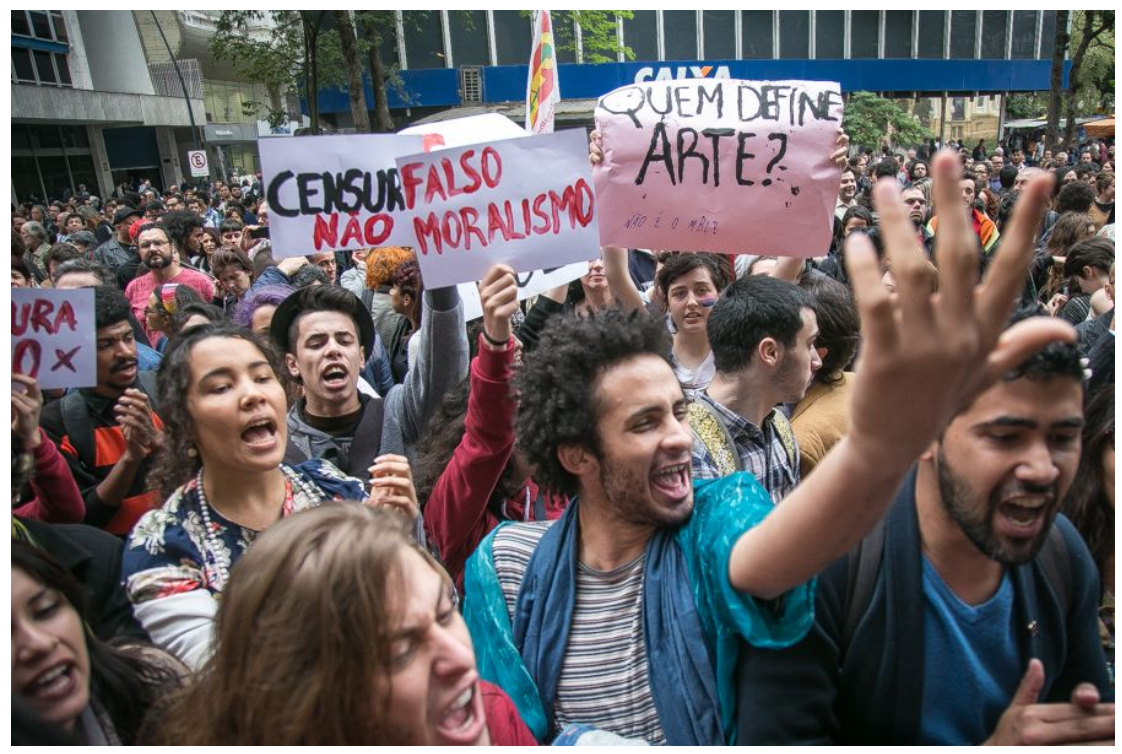

Fonte: Guilherme Santos/ Sul 21. Setembro de 2017.

Mas, se por um lado o fechamento da Queermuseu suscitou autocensura e temor, por outro, houve resistência da sociedade aos ataques. Em Porto Alegre, no dia 12 de setembro, logo após o fechamento da mostra, ocorreu uma significativa manifestação em frente ao Santander Cultural defendendo a exposição (cf. figura 9). Também nos meses seguintes, o meio artístico se organizou e realizou a maior campanha de financiamento coletivo já realizada no país, que 
coletou mais de um milhão de reais entre centenas de doadores individuais e viabilizou a reabertura da Queermuseu. Em agosto de 2018, agora em novo formato, a mostra foi exibida na Escola de Artes Visuais do Parque Lage, instituição pública ligada ao Estado do Rio de Janeiro. O evento atraiu um grande público e propiciou a ampliação do debate sobre o teor das obras e o fechamento da mostra em Porto Alegre. Como a história tem demonstrado, a resiliência coletiva vem se mostrando um antídoto efetivo contra a censura, o conservadorismo e o retrocesso.

\section{Referências bibliográficas}

CAVAZZOLA JUNIOR, Cesar Augusto. Santander promove pedofilia, pornografia e arte profana em Porto Alegre. Lócus Online. 6 set. 2017. Disponível em: www.locusonline.com.br/2017/09/06/santandercultural-promove-pedofilia-pornografia-e-arte-profana-em-porto-alegre/.

CITIZENGO. Repúdio à exposição blasfema do Santander Cultural. Citizengo, 9 de set. 2017. Disponível em: <www.citizengo.org/pt-pt/sc/88583-repudio-exposicao-blasfema-do-santander-cultural >.

DUARTE, Luísa (Org.) Arte Censura Liberdade: reflexões à luz do presente. Rio de Janeiro, RJ: Cobogó, 2018.

FIDELIS, Gaudêncio. (Org.) Queermuseu: cartografias da diferença na arte brasileira. Porto Alegre, RS: Santander Cultural, 2017.

FIDELIS, Gaudêncio. "Eu recebi mais de cem ameaças de morte", diz curador da exposição Queermuseu. El País, 28 de ago. 2018. Cultura. Disponível em: <brasil.elpais.com/brasil/2018/08/28/cultura/1535483191 606318.html>.

G1 RS. Museu de Porto Alegre encerra exposição sobre diversidade sexual após ataques em redes sociais. 10 set. 2019. G1. Disponível em: <https://g1.globo.com/rs/rio-grande-do-sul/noticia/museu-de-portoalegre-encerra-exposicao-sobre-diversidade-apos-ataques-em-redes-socias.ghtml>.

GUIMARÃES, Hellen; RESENDE, Leandro. O Santander perdeu mesmo mais de 20 mil clientes em apenas dois dias? Agência Pública, 16 de set. 2017. Lupa. Disponível em: <apublica.org/2018/08/eu-recebimais-de-cem-ameacas-de-morte-diz-curador-da-exposicao-queermuseu/>. Acesso em: $10 \mathrm{de}$ mar. de 2021. 
JAMIN, Jérôme. Cultural Marxism and the Radical Right. In: JACKSON, Paul, SHEKHOVTSOV, Anton (Orgs.) The post-war Anglo-American far right: a special relationship of hate. Londres, UK: Palgrave Macmillan, 2014.

MIGUEL, Luis Felipe. Da "doutrinação marxista” à "ideologia de gênero" - Escola Sem Partido e as leis da mordaça no parlamento brasileiro. Revista Direito e Práxis. Rio de Janeiro, v. 7, n. 3, p. 509-621, set., 2016.

MONITOR DO DEBATE POLÍTICO NO MEIO DIGITAL. Uma exposição do Santander Cultural foi envolvida em mais um capítulo das guerras culturais no Brasil. 11 de set. 2017. Facebook: monitor do debate político. Disponível em: <www.facebook.com/monitordodebatepolitico/posts/1535646699830121>. Acesso em: 11 de mar. 2021.

SANTANDER BRASIL. Nota sobre a exposição Queermuseu. 10 de set. 2018. Santander Brasil - Facebook. Disponível em: <www.facebook.com/santanderbrasil/posts/10154720373470588/>.

TAVARES, Flávia; AMORIM, Daniele. Como movimentos ultraconservadores conseguiram fechar a exposição Queermuseu. 0 Globo, 16 de set. 2017. Revista Época. Disponível em: < epoca.oglobo.globo.com/brasil/noticia/2017/09/como-movimentos-ultraconservadores-conseguiramencerrar-exposicao-queermuseu.html>.

ZERO HORA, Mostra é cancelada após críticas. Jornal Zero Hora, 11 de set. 2017. Disponível em: < gauchazh.clicrbs.com.br/geral/noticia/2017/09/queermuseu-mostra-e-cancelada-apos-ataques-emredes-sociais-9892968.html>.

\section{Vídeos:}

DENÚNCIA: SANTANDER INCENTIVA A PEDOFILIA! 7 min, color. Rafinha BK, 2017. Disponível em: $<\underline{\text { https://www.youtube.com/watch?v=OWNQNFuSKBY> }}$

EXPOSIÇÃO CRIMINOSA NO SANTANDER CULTURAL. 4 min, color. Terça Livre, 2017. Disponível em: <https://www.facebook.com/1499604770306657/videos/1906769406256856>

PEDOFILIA, ZOOFILIA E HÓSTIA DE VAGINA. 6 min 05s, color. Felipe Diehl, 2017. Disponível em: <https://www.facebook.com/magnomalta/videos/1575533122490439>

QUEERMUSEU PORTO ALEGRE - PROTESTOS, DENÚNCIAS E CANCELAMENTO. 5 min, color. Márcio Strzalkowski, 2017. Disponível em: <https://www.youtube.com/watch?v=oEyk4-rXxxI> 